\title{
Phosphonoacetic Acid in the Treatment of Experimental Ocular Herpes Simplex Infections
}

\author{
ROGER F. MEYER,' EMILY D. VARNELL, AND HERBERT E. KAUFMAN* \\ Department of Ophthalmology, College of Medicine, University of Florida, Gainesville, Florida 32610
}

Received for publication 23 September 1975

\begin{abstract}
Phosphonoacetic acid had a significant antiviral effect when applied topically, both in liquid and ointment preparations, on superficial herpetic keratitis in rabbits and was equally as effective as idoxuridine. It was also effective in the treatment of idoxuridine-resistant herpetic keratitis. Phosphonoacetic acid was not effective in the treatment of experimental herpetic iritis when applied topically but was significantly effective when administered intravenously and subconjunctivally. No significant local or systemic toxicity was encountered.
\end{abstract}

Phosphonoacetic acid (PAA) is a simple compound that is not an antimetabolite yet has been shown to inhibit herpes simplex virus (HSV) both in vitro and in vivo. A study by Shipkowitz et al. (10) in 1973 first showed that PPA suppressed HSV in tissue cultures, in herpetic dermatitis in mice, and in herpetic keratitis in rabbits. Recently, Gerstein et al. (3) showed that topical PAA was able to suppress clinical disease and virus replication in established herpetic keratitis in rabbits and was equivalent to idoxuridine (IDU) ointment. PAA appears to achieve its antiviral effect by inhibiting viral deoxyribonucleic acid (DNA) synthesis (8). Preliminary results have indicated that PAA specifically inhibits the viral DNAdependent DNA polymerase (7) and does not inhibit normal cellular DNA polymerases. Since PAA is not an antimetabolite and has no significant effect on host ribonucleic acid or DNA synthesis, we designed a series of experiments to compare PAA against other antiviral agents and to test its effect against deeper ocular herpetic infections and IDU-resistant keratitis in rabbits.

\section{MATERIALS AND METHODS}

New Zealand white rabbits weighing 2 to $4 \mathrm{lb}$ (about 9 to $18 \mathrm{~kg}$ ) were used for the study. All eyes were examined before each experiment to include only those free of disease. McKrae strain HSV with a titer of $1.6 \times 10^{6}$ plaque-forming units per $\mathrm{ml}$ prepared in human embryonic kidney cultures was used as the infective agent in most studies. The IDUresistant virus was prepared from an earlier passage of McKrae virus and made IDU resistant by growth in the presence of IDU in the medium.

To produce a superficial herpetic keratitis, the

' Present address: Department of Ophthalmology, University of Michigan, Ann Arbor, Mich. 48103. anesthetized cornea was gently abraded with a needle, making four epithelial scratches in a crosshatch pattern. A drop of virus was placed on the cornea and the lids were gently rubbed over the lesions for several seconds. The eyes were examined in a single blind fashion by a single examiner using a slit lamp with a cobalt blue filter after fluorescein staining. The epithelial keratitis was graded on a scale of 0 to $4+$, where zero represented no lesions and $1+$ involved one-fourth the area of the cornea up to $4+$, where the entire area of the cornea was covered with lesions. Both eyes of each animal were infected and treated identically throughout each experiment. Treatment of the keratitis was started on day 3 postinfection and continued daily for 5 days.

Experimental herpetic iritis was produced by injecting $0.1 \mathrm{ml}$ of a 1:5 dilution of the virus into the anterior chamber, using a 27-gauge needle on a tuberculin syringe. Before injection, the animals were sedated with intramuscular Thorazine and the corneas were topically anesthetized. The eyes were examined with a penlight and the iritis was graded on a scale of 0 to $4+$. Zero indicated no iritis, mild iris injection was graded as $1+$, moderate iris injection with edema was $2+$, severe iris hyperemia and edema was $3+$, and the presence of a hypopyon was graded as $4+$. During the natural course of the iritis, maximum infection occurs on day 7 or 8 postinfection. Treatment of the iritis was started on the day 1 postinfection and continued daily for 8 days.

The water-soluble disodium salt of PAA was used throughout the study (Abbott Laboratories, North Chicago, Ill.). Topical preparations were either 5\% solution in saline or $5 \%$ ointment in a petrolatum base. The intravenous preparation was in a concentration of $150 \mathrm{mg} / \mathrm{ml}$ dissolved in saline and given in a dosage of $150 \mathrm{mg} / \mathrm{kg}$ per day in a single daily dose. The subconjunctival preparation was in a concentration of $400 \mathrm{mg} / \mathrm{ml}$ in normal saline with a $\mathrm{pH}$ of 6.1 and was given as $0.25 \mathrm{ml}(100 \mathrm{mg})$ injected beneath the conjunctiva superiorly once per day in each eye for 8 days. 
The levels of severity of infection of the treatment groups were compared against one another each day by using the Kruskal-Wallis one-way analysis of variance (4). If the test statistic was significant at the $5 \%$ level of significance, multiple comparisons were then made on all treatment groups by using Dunn's technique (2). These tests were run at the $1 \%$ level of significance.

\section{RESULTS}

The 5\% PAA ointment was compared to the commercially available $0.5 \%$ Stoxil ointment (IDU) for effect on treating superficial keratitis. When both ointments were used four times per day there was no difference found between the healing promoted by the two agents, and both produced results significantly better than the control ointment (Table 1) on treatment days 4 and 5 when the controls were most severe.

When $5 \%$ PAA drops or $0.1 \%$ Stoxil drops were administered every $2 \mathrm{~h}$ around the clock to another group of animals, the severity of keratitis of both the PAA- and Stoxil-treated eyes was similar, and on day 5 both treatments were significantly better than the controls (Table 2).

A simultaneous comparison of the 5\% PAA drops and ointment was made, and both were compared with the Stoxil ointment. When all medications were given four times per day and evaluated on treatment days 4 and 5, all three treatment groups had significantly less severe keratitis than the controls. No significant difference was found between the PAA drops and ointment; both were equally effective (Table 3 ).

In a trial against IDU-resistant herpes keratitis, 5\% PAA drops administered six times a day was as effective as $1 \%$ trifluorothymidine drops on treatment days 4 and 5 . The severity of keratitis of both treatment groups was significantly less than the controls (Table 4).

TABLE 1. Effect of 5\% PAA ointment on superficial keratitis

\begin{tabular}{llll}
\hline \multirow{2}{*}{ Treatment $^{n}$} & & \multicolumn{3}{c}{$\begin{array}{c}\text { Severity of keratitis } \\
\text { on treatment day: }\end{array}$} \\
\cline { 2 - 4 } & & \multicolumn{1}{c}{4} & 5 \\
\hline 5\% PAA ointment $\ldots \ldots \ldots \ldots$ & $0.16^{c}$ & $0.22^{c}$ \\
0.5\% Stoxil ointment $\ldots \ldots \ldots \ldots$ & $0.29^{c}$ & $0.27^{c}$ \\
Control ointment ${ }^{d} \ldots \ldots \ldots \ldots$ & 0.78 & 1.94 \\
\hline
\end{tabular}

" All treatments were given four times daily; 40 eyes were tested with each treatment. Treatment started 3 days after infection and continued for 5 days.

${ }_{b} 0$, Normal cornea; 4 , complete corneal ulceration.

c Significantly better than control.

${ }^{d}$ Ointment base of liquid petrolatum and white petrolatum.
TABLE 2. Effect of 5\% PAA drops on superficial keratitis

\begin{tabular}{|c|c|c|}
\hline \multirow{2}{*}{ Treatment $^{a}$} & \multicolumn{2}{|c|}{$\begin{array}{l}\text { Severity of keratitis } \\
\text { on treatment day: }\end{array}$} \\
\hline & 4 & 5 \\
\hline $5 \%$ PAA drops & 0.95 & $0.60^{c}$ \\
\hline $0.1 \%$ Stoxil & 1.13 & $0.47^{c}$ \\
\hline Saline control & 1.16 & 1.36 \\
\hline
\end{tabular}

"All treatments were given every $2 \mathrm{~h} ; 20$ eyes were tested with each treatment. Treatment started 3 days after infection and continued for 5 days.

${ }^{b} 0$, Normal cornea; 4 , complete corneal ulceration.

c Significantly better than control.

TABLE 3. Comparison of 5\% PAA drops and ointment in treatment of superficial keratitis

\begin{tabular}{llll}
\hline \multicolumn{1}{c}{ Treatment } & & \multicolumn{3}{c}{$\begin{array}{c}\text { Severity of keratitis } \\
\text { on treatment day: }\end{array}$} \\
\cline { 2 - 4 } & & \multicolumn{1}{c}{4} & \multicolumn{1}{c}{5} \\
\hline 5\% PAA drops $\ldots \ldots \ldots \ldots \ldots \ldots$ & $0.77^{c}$ & $0.76^{c}$ \\
5\% PAA ointment $\ldots \ldots \ldots \ldots \ldots$ & $0.75^{c}$ & $0.53^{c}$ \\
0.5\% Stoxil ointment $\ldots \ldots \ldots \ldots$ & $0.35^{c}$ & $0.20^{c}$ \\
Saline control $\ldots \ldots \ldots \ldots \ldots \ldots$ & 1.52 & 1.67 \\
\hline
\end{tabular}

" All treatments were given four times daily; 20 eyes were tested with each treatment. Treatment started 3 days after infection and continued for 5 days.

${ }^{b} 0$, Normal cornea; 4 , complete corneal ulceration.

c Significantly better than controls. No difference in effect of PAA drops or ointment.

TABLE 4. Effect of 5\% PAA drops in IDU-resistant herpes keratitis

\begin{tabular}{llll}
\hline \multirow{2}{*}{ Treatment $^{n}$} & \multicolumn{3}{c}{$\begin{array}{c}\text { Severity of keratitis } \\
\text { on treatment day: }\end{array}$} \\
\cline { 2 - 4 } & & \multicolumn{1}{c}{4} & 5 \\
\hline 5\% PAA drops & $\ldots \ldots \ldots \ldots \ldots \ldots$ & $0.95^{c}$ & $0.75^{c}$ \\
1\% Trifluorothymidine drops & $\ldots$ & $0.73^{c}$ & $0.60^{c}$ \\
Saline control & $\ldots \ldots \ldots \ldots \ldots \ldots$ & 1.29 & 1.45 \\
\hline
\end{tabular}

a All treatments were given six times daily; 20 eyes were tested with each treatment. Treatment started 3 days after infection and continued for 5 days.

${ }^{b} 0$, Normal cornea; 4 , complete corneal ulceration.

c Significantly better than controls. No difference in effect of PAA or trifluorothymidine.

Topically applied 5\% PAA had no therapeutic effect on herpetic iritis (Table 5); however, the intravenous administration of $150 \mathrm{mg}$ of PAA per $\mathrm{kg}$ per day was effective in treating the iritis (Table 6). The group of animals treated with intravenous PAA and a group treated 
TABLE 5. Effect of 5\% PAA ointment on herpetic iritis

\begin{tabular}{|c|c|c|c|}
\hline \multirow{2}{*}{ Treatment" } & \multicolumn{3}{|c|}{$\begin{array}{l}\text { Severity of iritis }{ }^{b} \text { on } \\
\text { treatment day: }\end{array}$} \\
\hline & 4 & 7 & 9 \\
\hline $\begin{array}{l}\text { 5\% PAA ointment } \\
\text { Control ointment }\end{array}$ & $\begin{array}{l}2.06 \\
2.50\end{array}$ & $\begin{array}{l}1.79 \\
1.91\end{array}$ & $\begin{array}{l}1.65 \\
1.20\end{array}$ \\
\hline
\end{tabular}

"All treatments were given six times daily; 20 eyes were tested with each treatment. Treatment started 1 day after infection and continued for 9 days.

${ }^{b} 0$, Normal eye; 1 , mild iritis, to 4 , severe iritis with hypopyon.

with topical 5\% trifluorothymidine showed less severe iritis than the controls throughout most of the treatment period, with a significant difference noted on day 6 (Table 6). Subconjunctival injection of $100 \mathrm{mg}$ of PAA per day was also effective for the treatment of this experimental iritis. By the 3rd treatment day, both the PAA- and trifluorothymidine-treated eyes had less severe iritis than the controls. A significant difference was found between the PAA-treated group and controls on days $4,5,6$, and 7 (Table 7).

\section{DISCUSSION}

The majority of antiviral agents known to ophthalmology, including IDU, adenine arabinoside, cytosine arabinoside, and trifluorothymidine, are antimetabolites. These drugs have been researched primarily for use in cancer chemotherapy. Because they are inhibitors of DNA synthesis they have also been found beneficial in viral chemotherapy. PAA (Fig. 1), not an antimetabolite, appears now also to possess significant antiviral activity. When applied topically, either as an ointment or a drop, it causes a statistically significant suppression of experimental herpetic keratitis in rabbits. It appears to be as effective as IDU. Since the epithelial ulcer of herpetic keratitis is the direct cause of multiplying virus, this is the only parameter measured. Halting virus multiplication allows the ulcers to heal and provides a direct measure of antiviral efficacy. We therefore did not include other parameters that are not directly caused by virus multiplication.

Punctate epithelial toxicity, similar to that encountered with topical IDU, has been reported with the use of topical 5\% PAA drops given eight times a day and has disappeared within $48 \mathrm{~h}$ after cessation of the medication (3). However, when given six times a day for 5 days to five uninfected rabbits, we found no
TABLE 6. Effect of intravenous PAA on herpetic iritis

\begin{tabular}{|c|c|c|c|c|}
\hline \multirow{2}{*}{ Treatment $^{n}$} & \multicolumn{4}{|c|}{ Severity of iritis ${ }^{b}$ on treatment day: } \\
\hline & 4 & 5 & 6 & 7 \\
\hline $\begin{array}{l}\text { Intravenous PAA, } \\
150 \mathrm{mg} / \mathrm{kg} / \text { day in } \\
\text { single daily dose. }\end{array}$ & 0.88 & 0.90 & $0.93^{c}$ & 0.68 \\
\hline $\begin{array}{l}\text { 5\% Trifluorothymi- } \\
\text { dine drops, } 6 \\
\text { times daily } \ldots .\end{array}$ & 0.96 & 0.80 & $0.61^{c}$ & 0.46 \\
\hline $\begin{array}{c}\text { Saline control, } 6 \\
\text { times daily } \ldots .\end{array}$ & 1.31 & 1.52 & 1.42 & 1.27 \\
\hline
\end{tabular}

"All treatment started 1 day after infection and continued for 7 days; 24 eyes were tested with each treatment.

${ }^{b} 0$, Normal eye; 1 , mild iritis, to 4 , severe iritis with hypopyon.

c Significantly better than controls.

TABLE 7. Effect of subconjunctival PAA on herpetic iritis

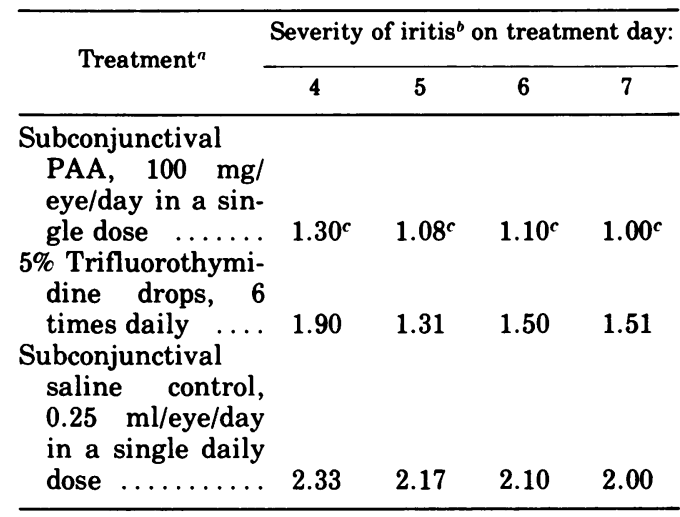

"All treatments started 1 day after infection and continued for 7 days; 24 eyes were tested with each treatment.

${ }^{b} 0$, Normal eye; 1 , mild iritis, to 4 , severe iritis in the hypopyon.

c Significantly better than controls.

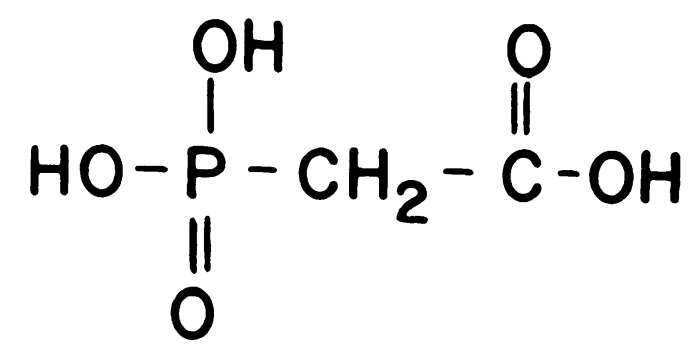

Fig. 1. Phosphonoacetic acid structure.

epithelial toxicity. Our toxicity testing was done in nonscarified eyes, however, and there is the possibility that trauma could alter the response to phosphonoacetic acid. 
Earlier reports indicated that systemic administration of PAA, up to $300 \mathrm{mg} / \mathrm{kg}$ per day either orally (10) or intraperitoneally (6), was well tolerated in mice. Intravenous PAA, in a concentration of $300 \mathrm{mg} / \mathrm{kg}$, produced severe tetanic muscular spasms in rabbits, often resulting in death. When the dosage was reduced to $150 \mathrm{mg} / \mathrm{kg}$ in a concentration of $75 \mathrm{mg} / \mathrm{ml}$, it was well tolerated when given as a slow intravenous push. No gross evidence of systemic toxicity was noted; however, pathological examination was not done at this time. Intravenous PAA produced a significant suppression of experimental herpetic iritis in rabbits. However, when given topically it was not effective. Only two other antiviral agents have been shown to suppress experimental herpetic iritis: topical 5\% trifluorothymidine (11) and intravenous adenine arabinoside (1).

PAA, given subconjunctivally in an initial dosage of $150 \mathrm{mg} /$ eye, caused necrosis of the surrounding conjunctiva and sclera. However, when the concentration was reduced from 600 to $400 \mathrm{mg} / \mathrm{ml}$, delivering $100 \mathrm{mg} / 0.25 \mathrm{ml}$ to each eye subconjunctivally, no conjunctival or scleral necrosis was noted. Disodium phosphonoacetate in a concentration of $400 \mathrm{mg} / \mathrm{ml}$ has a $\mathrm{pH}$ of 6.1 , which was well tolerated by the tissues. There was essentially no difference in the amount of conjunctival inflammation noted between uninfected eyes receiving $100 \mathrm{mg}$ of PAA or $0.25 \mathrm{ml}$ of saline subconjunctivally. PAA given subconjunctivally significantly suppressed experimental herpetic iritis in rabbits.

Strains of HSV resistant to the antiviral effect of IDU are not uncommon (5) and will continue to be a problem as long as only one commercially available antiviral agent exists. These experiments show that IDU-resistant HSV keratitis can be successfully suppressed with PAA. The development of resistance to IDU does not appear to be accompanied by resistance to PAA. This is not uncommon, for it has also been shown that strains of HSV resistant to PAA are still amenable to treatment with adenine arabinoside (6). This is con- sistent with the data showing that IDU resistance in HSV populations does not influence susceptibility to other antiviral agents (9). Since IDU resistance is not an uncommon problem, it would be highly desirable to have alternative antiviral agents available for these patients.

\section{ACKNOWLEDGMENT}

Statistical analyses were performed by Ron Marks of the Biostatistics Units of the College of Medicine.

\section{LITERATURE CITED}

1. Abel, R., Jr., H. E. Kaufman, and J. Sugar. 1975. The effect of intravenous adenine arabinoside against herpes simplex keratouveitis in humans. Am. J. Ophthalmol. 79:659-666.

2. Dunn, O. J. 1964. Multiple comparisons using rank sums. Technometrics 6:241-252.

3. Gerstein, D. D., C. R. Dawson, and J. O. Oh. 1975. Phosphonoacetic acid in the treatment of experimental herpes simplex keratitis. Antimicrob. Agents Chemother. 7:285-288.

4. Hollander, M., and D. A. Wolf. 1973. Nonparametric statistical methods, p. 129-130. Wiley and Sons, New York.

5. Jawetz, E., V. R. Coleman, C. R. Dawson, and P. Thygeson. 1970. The dynamics of IUDR action in herpetic keratitis and the emergence of IUDR resistance in vivo. Ann. N.Y. Acad. Sci. 173:282-291.

6. Klein, R. J., and A. E. Friedman-Kien. 1975. Phosphonoacetic acid-resistant herpes simplex virus infection in hairless mice. Antimicrob. Agents Chemother. 7: 289-293.

7. Mao, J. C. H., E. E. Robishaw, and L. R. Overby. 1975. Inhibition of DNA polymerase from herpes simplex virus-infected Wi-38 cells by phosphonoacetic acid. J. Virol. 15:1281-1283.

8. Overby, L. R., E. E. Robishaw, J. B. Schleicher, A. Rueter, N. L. Shipkowitz, and J. C. H. Mao. 1974. Inhibition of herpes simplex virus by phosphonoacetic acid. Antimicrob. Agents Chemother. 6:360365.

9. Renis, H. E., and D. A. Buthala. 1965. Development of resistance to antiviral drugs. Ann. N.Y. Acad. Sci. 130:343-354.

10. Shipkowitz, N. L., R. R. Bower, R. N. Appell, C. W. Nordeen, L. R. Overby, W. R. Roderick, J. B. Schleicher, and A. M. Von Ech. 1973. Suppression of herpes simplex virus infection by phosphonoacetic acid. Appl. Microbiol. 26:264-267.

11. Sugar, J., E. Varnell, Y. Centifanto, and H. E. Kaufman. 1973. Trifluorothymidine treatment of herpetic iritis in rabbits and ocular penetration. Invest. Ophthalmol. 12:532-534. 